\title{
Análise de resultados de auditorias ambientais de homologação de empresas de tratamento de resíduos sólidos, provenientes de uma indústria automobilística
}

As auditorias de homologação reúnem um conjunto de vários tipos de auditorias envolvendo diversas avaliações de requisitos legais. Neste sentindo o presente trabalho teve por objetivo analisar os resultados de auditorias ambientais de homologação em empresas de tratamento de resíduos sólidos que utilizam processos de reciclagem, coprocessamento, incineração e disposição em aterros provenientes de uma indústria automobilística, geradora de aproximadamente 56.473 toneladas/ano de resíduos sólidos. Resíduos estes, classificados como do tipo Classe I e Classe II. Durante o período de 24 meses, foram realizadas 29 auditorias em empresas de tratamento de resíduos sólidos, e em cada auditoria foram verificados 18 quesitos, obtendo-se um total de 522 quesitos. A partir da análise dos quesitos auditados verificou-se que as empresas de grande porte independentemente do tipo de tratamento utilizado, apresentaram os melhores resultados com relação ao cumprimento dos requisitos legais. Com base nos resultados avaliados, observou-se que, dos resíduos tratados no período avaliado, $83 \%$ foram enviados à reciclagem, e em torno de $14 \%$ tiveram como destinado o coprocessamento, $3 \%$ Aterro e menos de $1 \%$ para incineração. Dentre as empresas de pequeno porte que apresentaram maior risco ambiental à geradora de resíduos sólidos destacou-se a de incineração, com apenas $58 \%$ de atendimento aos requisitos legais aplicáveis, seguida da empresa de reciclagem, que obteve $64 \%$ de atendimento aos quesitos avaliados, por sua vez as empresas de coprocessamento, obtiveram um resultado de $95 \%$

Palavras-chave: Auditoria Ambiental; Legislação Ambiental; Resíduos Sólidos; Indústria Automobilística.

\section{Analysis of the results of the environmental audits of approval of companies for the treatment of solid waste, arising from an automobilistic industry}

\begin{abstract}
Approval audits are a set of various types of audits, involving assessments of legal requirements. In this sense, the objective of this work was to analyze the results of environmental audits of approval of solid waste treatment companies that use recycling, co-processing, incineration and disposal in landfills from an automobile industry, generating approximately 56,473 tons/year of solid waste. These wastes, classified as being Class I and Class II. During the $24-m o n t h, 29$ audits were carried out in solid waste treatment companies, and in each audit 18 questions were verified, resulting in a total of 522 questions. Based on the evaluated results, it was observed that, of the waste treated in the evaluated period, $83 \%$ were sent for recycling, and around $14 \%$ were destined for co-processing, $3 \%$ Landfill and less than $1 \%$ for incineration. Among the small companies that presented the greatest environmental risk to the solid waste generator, incineration stood out, with only $58 \%$ of compliance with the applicable legal requirements, followed by the recycling company, which obtained $64 \%$ of compliance with the assessed requirements, in turn, the co-processing companies obtained a result of $95 \%$.
\end{abstract}

Keywords: Environmental Auditing; Environmental Legislation; Solid Wastes; Automobile industry; Carmaker..

Topic: Planejamento, Gestão e Políticas Públicas Ambientais

Reviewed anonymously in the process of blind peer.
Received: 04/04/2021

Approved: 28/04/2021
Gisele Hahn Barbieri (1D

Universidade Federal do Paraná, Brasil

http://lattes.cnpq.br/4496335877860152

http://orcid.org/0000-0002-4607-027X

gisele.barbieri@inter.ikea.com

Arislete Dantas de Aquino (iD

Universidade Federal do Paraná, Brasil

http://lattes.cnpq.br/8543730275673239

http://orcid.org/0000-0002-9960-2639

arislete@ufpr.br 


\section{INTRODUÇÃO}

A indústria automobilística, apesar de seus rigorosos controles ambientais, pode gerar impactos ambientais significativos em toda a sua cadeia produtiva, sendo estes impactos observados desde o início da extração da sua matéria prima, nos seus processos industriais, como estamparia, solda, pintura e montagem, no seu produto final, na disposição final de seus resíduos e após o ciclo de vida do veículo.

Com a evolução das indústrias automobilísticas, além do desenvolvimento econômico, também houve a proliferação de grande número de veículos automotores, ocasionando mudanças consideráveis que afetaram o equilíbrio natural do planeta e colocando em risco a sobrevivência do homem e de vários ecossistemas em todo o mundo.

Neste sentindo nas últimas décadas é crescente a demanda pela utilização de práticas que levem à conservação de ecossistemas e de condições de trabalho no setor industrial e fatores como a legislação, a preocupação dos consumidores com o meio ambiente e a qualidade dos produtos têm levado as organizações industriais a repensarem suas estratégias e otimizarem seus processos produtivos a curto, médio e longo prazo.

As auditorias ambientais são, de acordo com Vélez et al. (2017) uma ferramenta técnica disponível para identificar áreas ambientalmente críticas e formular soluções apropriadas de gerenciamento, além de ser um processo sistemático, independente e documentado, que permite obter informações e avaliá-las objetivamente, a fim de se determinar a conformidade com os padrões do sistema de gerenciamento, com as legislações vigentes e a política ambiental da empresa. Moreira et al. (2018) complementam que a auditoria é um conjunto de procedimentos que tem por objetivo examinar e adequar a eficácia dos Controles, e também uma revisão das operações das empresas, para verificar se ela enquadra as normas pertinentes.

\section{REVISÃO TEÓRICA}

A auditoria ambiental é uma atividade voluntária para a maioria das organizações e nas últimas décadas, o número de organizações que dependem de auditorias ambientais vem aumentando exponencialmente devido à importância e a necessidade cada vez mais crescente de controle e gestão ambiental nas empresas.

As auditorias ambientas surgiram da pressão e da exigência do mercado internacional, e assim as organizações começaram a buscar na preservação do meio ambiente um diferencial de competitividade, e como consequência, observou-se um aumento do número de empresas com o Sistema de Gerenciamento Ambiental (SGA) implantado. Os SGAs precisam ser verificados e avaliados, a fim de garantir a eficiência no cumprimento dos objetivos preestabelecidos pelas empresas, e para que a verificação seja realizada começase a implantar a auditoria ambiental como uma ferramenta para contribuir com a eficácia do sistema, atendimento aos requisitos legais e melhores resultados gerenciais (VIEIRA, 2011).

Todea et al. (2011) afirmam que o Conselho da União Europeia define auditoria ambiental como uma ferramenta que consiste em avaliação sistêmica, documentada, objetiva e regular do desempenho, do 
Análise de resultados de auditorias ambientais de homologação de empresas de tratamento de resíduos sólidos, provenientes de uma indústria

sistema de gestão e dos processos destinados a proteger o meio ambiente, a fim de controlar as práticas que tem impacto ambiental e avaliar a sua conformidade com as políticas ambientais existentes.

Segundo Ingole (2012) o conceito de auditoria ambiental surgiu nos Países industrializados, como Canadá, EUA, Reino Unido e Holanda, no início dos anos 70. Já em 1972, o grupo British Petroleum (B.P.) International usou este conceito pela primeira vez para alertar sobre a importância da prática da realização de auditorias nas indústrias.

Por sua vez, Tai et al. (2013) afirmam que as auditorias ambientais são vistas nos países do oriente como um tipo de atividade de gerenciamento do controle de custos ambientais, que tem como objetivo garantir a utilização sustentável dos recursos naturais com base em sua prestação de contas.

No Brasil a auditoria ambiental surgiu por meio de legislações da década de 1990. Porém, foi a Associação Brasileira de Normas Técnicas - ABNT que primeiro apresentou, em dezembro de 1996, um conjunto completo de normas que, de fato, contêm os princípios, as diretrizes e os critérios salutares para o desenvolvimento dos trabalhos de auditoria, dentre elas: NBR ISO 14010, 14011 e 14012 (QUEIROZ, 2017).

Deste modo, a auditoria de homologação de prestadores de serviços de tratamento de resíduos tem como objetivo principal caracterizar a situação ambiental destas empresas fornecendo um diagnóstico atual dos controles exercidos, favorecendo a definição das ações de minimização, mitigação e de gerenciamento.

Assim, as auditorias ambientais foram utilizadas como uma alternativa sistêmica para as empresas se prevenirem de danos futuros, cumprirem seus objetivos, atingirem suas metas sociais, estarem em concordância com a legislação ambiental e principalmente garantir a responsabilidade compartilhada de seus produtos, da cadeia produtiva e também dos resíduos sólidos Classe I e Classe II gerados e tratados.

Segundo a NBR 10.004:2004 são considerados resíduos Classe I, aqueles resíduos que apresentam periculosidade, risco à saúde pública, risco ao meio ambiente, características de inflamabilidade, corrosividade, reatividade, toxicidade, patogenicidade ou ainda que constem nos anexos A ou B desta norma (ABNT, 2004).

Já os resíduos Classes II podem ser classificados em Classe IIA (não inertes) e em Classe IIB (inertes). Os resíduos Classe IIA são aqueles cujas propriedades apresentam biodegradabilidade, combustibilidade ou solubilidade em água e os Classe IIB são quaisquer resíduos que não tiverem nenhum de seus constituintes solubilizados a concentrações superiores aos padrões de potabilidade de água, excetuando-se aspecto, cor, turbidez, dureza e sabor, conforme anexo G na NBR 10.004 (ABNT, 2004).

\section{MATERIAIS E MÉTODOS}

A metodologia adotada neste trabalho constitui-se em uma abordagem qualitativa e quantitativa, que se materializou com a coleta de dados e análise dos resultados obtidos em empresas cujos nomes foram preservados, por questões de sigilo em seus processos produtivos.

A coleta de dados consistiu nas etapas de auditorias descritas por Córdova et al. (2016) e nas etapas de Característica da empresa geradora de resíduos; Característica das empresas auditadas; Auditoria 
Análise de resultados de auditorias ambientais de homologação de empresas de tratamento de resíduos sólidos, provenientes de uma indústria

ambiental de homologação; Verificação dos resultados obtidos nas auditorias ambientais de homologação e Avaliação dos resultados de homologação nos diferentes processos de tratamento.

\section{Etapas das Auditorias}

As principais atividades da etapa de Planejamento da auditoria, segundo Córdova et al. (2016), são contato inicial com o auditado, determinação da viabilidade, preparação das atividades, conclusão da revisão da documentação, preparação do plano de auditoria, atribuição das tarefas da equipe e preparação de documentos de trabalho; já na etapa de execução, as fase mais significativas são compreendidas da condução das atividades de auditoria, reunião de abertura, conclusão da revisão de documentação, atribuição de responsabilidades, recolhimento e verificação de informação e fechamento; na fase do relatório, as etapas principais são a preparação e distribuição do relatório de auditoria sua conclusão; a realização das atividades de acompanhamento se dá na etapa de seguimento.

\section{Características da empresa geradora de resíduos sólidos}

As informações sobre a empresa geradora foram obtidas por meio de verificação de notas fiscais, de relatórios de gestão de resíduos sólidos e resultados de auditorias de homologação realizadas pela própria empresa geradora de resíduos.

\section{Características das empresas auditadas}

Para a definição do perfil das empresas de tratamento de resíduos foram verificadas as seguintes características: Localização; Classe de resíduo; Tratamento ou tipo de disposição final; Número de empregados; Atividade principal; Área da empresa; Porte, e Quantidade de resíduos tratados.

As quantidades de resíduos gerados foram aquelas destinadas às empresas de tratamento de resíduos durante o período compreendido de 24 meses. A classificação dos resíduos entre Classe I e Classe II, foi obtida a partir de laudos de caracterização de resíduos sólidos conforme a NBR 10.004:2004.

A classificação quanto ao porte da empresa foi a mesma da elaborada pelo Serviço Brasileiro de Apoio às Micro e Pequenas Empresas - SEBRAE, com base no número de colaboradores existentes, como apresentado na Tabela 1.

Tabela 1: Porte da empresa.

\begin{tabular}{ll}
\hline & COMÉRCIO E SERVIÇO \\
PORTE DA EMPRESA & NÚMERO DE FUNCIONÁRIOS \\
Microempresa & Até 9 \\
Pequeno porte & 10 a 49 \\
Médio porte & 50 a 99 \\
Grande porte & $>99$ \\
\hline
\end{tabular}

\section{Auditoria ambiental de homologação}

As auditorias de homologação foram realizadas pela empresa geradora de resíduos sólidos e seguiram as premissas estabelecidas em procedimentos de auditoria de empresas de tratamento de resíduos 
Análise de resultados de auditorias ambientais de homologação de empresas de tratamento de resíduos sólidos, provenientes de uma indústria

sólidos, sendo considerados as seguintes etapas: Aplicação e responsabilidade; Objetivo; Frequência; Procedimento; Critério de aprovação e Termo de confidencialidade.

Cada uma destas etapas caracterizou-se em um processo de auditoria e geram resultados que foram utilizados para compor o relatório final de auditoria. Os percentuais para o critério aprovação seguiram a metodologia desenvolvida por Vandenbrande (1998) que classificou o risco em uma escala de 1 a 10 e segundo o autor os resultados compreendidos na faixa entre 1 a 6 são considerados como de alto risco; aqueles compreendidos entre 6 a 8 de risco moderado e acima de 8 de baixo risco.

\section{Verificação dos resultados obtidos nas auditorias ambientais de homologação}

Os resultados obtidos nas auditorias de homologação seguiram também a metodologia descrita Vandenbrande (1998) e criou seus próprios critérios de avaliação de riscos ambientais em escalas expressas em porcentagem variando de 0 a 100 e classificado o risco como alto, médio e baixo.

Sendo considerados como resultado final da auditoria de até $60 \%$, alto risco ambiental. Acima de $61 \%$ até $79 \%$, médio risco e resultados superiores a $80 \%$, aprovado sem restrições, representando baixo risco ambiental.

\section{Avaliação dos resultados de homologação nos diferentes processos de tratamento}

A análise dos resultados foi realizada de forma sistêmica, somente para os quesitos cujos resultados de atendimento legal apresentaram resultados inferiores a $80 \%$, ou seja, com risco ambiental considerado médio e alto, os demais, considerados de baixo risco, não foram avaliados neste trabalho.

Por sua vez Todea et al. (2011) consideram a avaliação sistêmica de resultados de auditorias como sendo uma análise capaz de controlar as práticas que ocasionam impactos ambientais e avaliar sua conformidade com as políticas ambientais existentes.

\section{RESULTADOS E DISCUSSÃO}

Os resultados e discussão foram descritos também nas etapas abordadas por Córdova et al. (2016) e nas etapas de Característica da empresa geradora de resíduos já mencionados neste trabalho:

\section{Etapas das Auditorias}

A etapa do planejamento da auditoria foi realizada primeiramente o contato com a empresa de tratamento de resíduos, a obtenção de informações relevantes do processo de tratamento de resíduos, preparação de documentos, preparação do plano de trabalho, verificação do escopo e agenda da auditoria, assim como a dos quesitos auditados.

Para a etapa de execução foram realizadas a Reunião de abertura, Apresentação do planejamento da auditoria; Visita às instalações para a análise dos processos de tratamento de resíduos; Verificação da documentação e Reunião de encerramento. 
Nesta etapa do relatório realizou-se a descrição final de auditoria documentada, formalizando o resultado da auditoria e seu desempenho, já as ações de contenção relacionadas às não conformidades descritas no relatório de auditoria foram aprovadas e gerenciadas pela empresa geradora de resíduos através de fotos, e-mails e evidências na etapa de seguimento da auditoria.

\section{Características da empresa geradora de resíduos sólidos}

A empresa geradora caracteriza-se como uma empresa de grande porte, com mais de 6.000 contratados diretos e 3.000 indiretos.

\section{Características das empresas auditadas}

No período compreendido entre 24 meses foram auditas 29 empresas de tratamento de resíduos sólidos, localizadas nos estados de Santa Catarina, São Paulo, Paraná e Pernambuco. Estas empresas foram classificadas de acordo com o tipo de tratamento empregado aos resíduos, ou seja: 24 empresas de reciclagem, 3 de coprocessamento, 1 de incineração e 1 de disposição final em aterro. A tabela 2 apresenta o perfil das empresas de tratamento de resíduos sólidos abordadas neste trabalho.

Tabela 2: Perfil das empresas de tratamento de resíduos auditadas.

\begin{tabular}{|c|c|c|c|c|c|c|c|c|c|}
\hline \multirow{2}{*}{$\mathbf{N}^{\circ}$} & \multirow{2}{*}{ ESTADO } & \multicolumn{2}{|c|}{ CLASSE } & \multirow{2}{*}{ TRAT. } & \multirow{2}{*}{$\begin{array}{l}\mathbf{N}^{\circ} \\
\text { EMP. }\end{array}$} & \multirow{2}{*}{ RESÍDUO } & \multirow{2}{*}{$\begin{array}{l}\text { ÁREA } \\
\left(m^{2}\right)\end{array}$} & \multirow{2}{*}{ PORTE } & \multirow{2}{*}{$\begin{array}{l}\text { RESÍDUOS } \\
\text { GERADOS (T) }\end{array}$} \\
\hline & & 1 & II & & & & & & \\
\hline 1 e 2 & PR & & $x$ & Reciclagem & 36 & $\begin{array}{lll}\text { Gordura } & \text { e } & \text { resíduos } \\
\text { orgânicos } & & \\
\end{array}$ & 1.115 & Pequeno & 10.95 \\
\hline 3 & $\mathrm{PR}$ & $\mathrm{X}$ & & Reciclagem & 25 & Bituca de cigarro & 5.337 & Pequeno & 0,8 \\
\hline 4 & $\mathrm{PR}$ & & $\mathrm{x}$ & Reciclagem & 3 & Plástico tipo I & 827 & Micro & 3,34 \\
\hline 5 & $\mathrm{PR}$ & $x$ & & Reciclagem & 8 & Emulsão oleosa & 828 & Micro & 1.105 \\
\hline 6 & SP & $x$ & & Reciclagem & 67 & $\begin{array}{l}\text { Eletrônicos } \\
\text { catalisadores }\end{array}$ & 4.356 & Médio & 14.97 \\
\hline 7 & $\mathrm{PR}$ & & $x$ & Reciclagem & 12 & \begin{tabular}{lll|}
$\begin{array}{l}\text { Tecidos, } \\
\text { espumas }\end{array}$ & retalhos $\quad$ e \\
\end{tabular} & 2.511 & Pequeno & 4,19 \\
\hline 8 & $\mathrm{PR}$ & & $\mathrm{x}$ & Reciclagem & 100 & Papel branco & 10.501 & Grande & 220,53 \\
\hline 9 & SP & $x$ & & Reciclagem & 1100 & $\begin{array}{|lll|}\begin{array}{l}\text { Rerrefino de óleo } \\
\text { lubrificante }\end{array} & \\
\end{array}$ & 16.216 & Grande & 101,56 \\
\hline 10 & $\mathrm{PR}$ & & $\mathrm{x}$ & Reciclagem & 6 & Madeira & 4.325 & Micro & $23.000,47$ \\
\hline 11 & $\mathrm{PR}$ & $x$ & & Reciclagem & 3 & Tintas e solventes & 309 & Micro & 80,28 \\
\hline 12 & $\mathrm{PE}$ & $\mathrm{X}$ & & Reciclagem & 262 & Baterias & 3.617 & Grande & 153,93 \\
\hline 13 & $\mathrm{SC}$ & & $\mathrm{x}$ & Reciclagem & 16 & Pneus & 1.559 & Pequeno & 80,58 \\
\hline 14 & $\mathrm{PR}$ & & $x$ & Reciclagem & 12 & Plásticos tipo II & 900 & Pequeno & 203,38 \\
\hline 15 & SP & & $x$ & Reciclagem & 45 & Lodos & 2.500 & Pequeno & $1.329,6$ \\
\hline 16 & $\mathrm{PR}$ & & $\mathrm{x}$ & Reciclagem & 19 & Plásticos tipo III & 1.056 & Pequeno & $2.980,44$ \\
\hline 17 & $\mathrm{PR}$ & $\mathrm{X}$ & $\mathrm{x}$ & Reciclagem & 10 & Entulho e borra de tinta & 1.074 & Pequeno & $1.678,71$ \\
\hline 18 & $\mathrm{SP}$ & $\mathrm{x}$ & & Reciclagem & 69 & Pilhas e baterias & 4.540 & Médio & 0,79 \\
\hline 19 & $\mathrm{PR}$ & $x$ & & Reciclagem & 92 & Embalagens industriais & 8.089 & Médio & 121,61 \\
\hline 20 & $\mathrm{PR}$ & & $\mathrm{x}$ & Reciclagem & 1200 & Papelão & 64.633 & Grande & $15.333,27$ \\
\hline 21 & $\mathrm{SC}$ & & $x$ & Reciclagem & 10 & Vidro & 3.300 & Pequeno & 150,14 \\
\hline 22 & $\mathrm{PR}$ & & $x$ & Reciclagem & 15 & Pneus e borracha & 624 & Pequeno & 63,71 \\
\hline $\begin{array}{l}23 \text { e } \\
24\end{array}$ & PR & $x$ & & Reciclagem & 11 & $\begin{array}{ll}\begin{array}{l}\text { Reciclagem } \\
\text { eletrônicos }\end{array} & \text { de } \\
\end{array}$ & 1.332 & Pequeno & 8,54 \\
\hline \multicolumn{9}{|c|}{ Total $=$} & $46.646,79$ \\
\hline 25 & PR & $x$ & & Coprocessamento & 19 & $\begin{array}{l}\text { Reaproveitamento } \\
\text { energético }\end{array}$ & 2.954 & Pequeno & $3.214,91$ \\
\hline 26 & SP & $x$ & & Coprocessamento & 55 & $\begin{array}{l}\text { Reaproveitamento } \\
\text { energético }\end{array}$ & 3.500 & Médio & $1.460,44$ \\
\hline 27 & $\mathrm{PR}$ & $x$ & & Coprocessamento & 600 & Reaproveitamento & 80.623 & Grande & $3.214,91$ \\
\hline
\end{tabular}


Análise de resultados de auditorias ambientais de homologação de empresas de tratamento de resíduos sólidos, provenientes de uma indústria

\begin{tabular}{|c|c|c|c|c|c|c|c|c|}
\hline & & & & & energético & & & \\
\hline \multicolumn{8}{|c|}{ Total = } & $7.890,26$ \\
\hline 28 & PR & $x$ & Incineração & 35 & $\begin{array}{l}\text { Tratamento de resíduos } \\
\text { da saúde }\end{array}$ & 700 & Pequeno & 1,59 \\
\hline 29 & PR & $x$ & Aterro & 103 & Lixo comum & 11.421 & Grande & $1.944,83$ \\
\hline \multicolumn{8}{|c|}{ TOTAL GERAL = } & $56.483,47$ \\
\hline \multicolumn{9}{|c|}{ Em que: Trat = Tratamento e $\mathrm{N}^{\circ} \mathrm{EMP}$. = Número de empresas. } \\
\hline
\end{tabular}

A maior parte das empresas de tratamento de resíduos estão localizadas no estado do Paraná, ou seja, 21 empresas, como apresentado na (Tabela 3). No que se refere a classificação dos resíduos, parte foram classificados como resíduos Classe I e parte como Classe II. A quantidade de resíduos tratados, segundo sua Classe, pode ser observada na tabela 4.

Tabela 3: Localização das empresas e tipo de tratamento.

\begin{tabular}{lll}
\hline ESTADOS & NÚMERO DE EMPRESAS & TIPO DE TRATAMENTO \\
\hline PR & 21 & Reciclagem, Coprocessamento, Aterro e Incineração. \\
SP & 5 & Reciclagem e Coprocessamento. \\
SC & 2 & Reciclagem. \\
PE & 1 & Reciclagem. \\
\hline Total & 29 & \\
\hline
\end{tabular}

Tabela 4: Quantidade de resíduo por classe nas empresas de tratamento.

\begin{tabular}{lll}
\hline \multirow{2}{*}{ EMPRESAS DE TRATAMENTO DE RESíDUOS CLASSE I E II } & \multicolumn{2}{l}{ QUANTIDADES (t) } \\
\cline { 2 - 4 } & CLASSE I & CLASSE II \\
\hline Reciclagem & $3.266,19$ & 43,380 \\
Coprocessamento & 7.890 & - \\
Incineração & 1,59 & - \\
Aterro & 1.945 & - \\
\hline Total & $\mathbf{1 3 . 1 0 3}$ & $\mathbf{4 3 . 3 8 0}$ \\
\hline Total Geral & $\mathbf{5 6 . 4 8 3}$ \\
\hline
\end{tabular}

A quantidade de resíduos gerados pelo período de 24 meses presentou a soma dos resíduos classificados como Classe I e Classe II, ou seja, 56.483 toneladas de resíduos. Também foi realizada uma análise por tipo de tratamento de resíduo Classe I, uma vez que este tipo de resíduo é capaz de causar maiores impactos ambientais se comparados aos resíduos Classe II, como é o caso dos resíduos de lodos, borras de tintas, emulsões oleosas, óleos lubrificantes, solventes, baterias e resíduos hospitalares. A figura 1 apresenta os tipos de empresas de tratamento de resíduos Classe I, suas quantidades e o percentual correspondente ao total gerado.

As empresas de coprocessamento trataram 7.890 toneladas de resíduos Classe I, representando 60\% do montante de resíduos Classe I. Já as empresas de reciclagem trataram 3.266 toneladas de resíduos, ou 25\% do montante dos resíduos Classe I. Para a empresa de aterro foram destinadas 1.945 toneladas de resíduos Classe I, representando $15 \%$ do montante total e a empresa de incineração tratou apenas 1,59 toneladas de resíduos, ou seja $0,012 \%$ do total dos resíduos Classe I. A figura 2 apresenta o perfil das empresas avaliadas, possibilitando a verificação da classificação do porte das empresas como sendo micro, pequeno, médio e grande porte.

As empresas de reciclagem foram classificadas como sendo: 5 empresas de micro porte; 12 de pequeno porte; 3 de médio porte e 4 de grande porte, sendo que a maior parte das empresas de reciclagem avaliadas neste trabalho foram de pequeno porte. As empresas de coprocessamento se classificaram em: 1 
Análise de resultados de auditorias ambientais de homologação de empresas de tratamento de resíduos sólidos, provenientes de uma indústria

pequeno, 1 médio e 1 grande porte. A empresa de incineração foi classificada como sendo de pequeno porte e a empresa de aterro, como de grande porte.

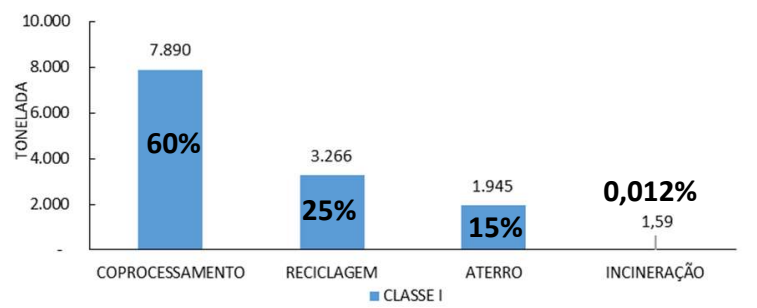

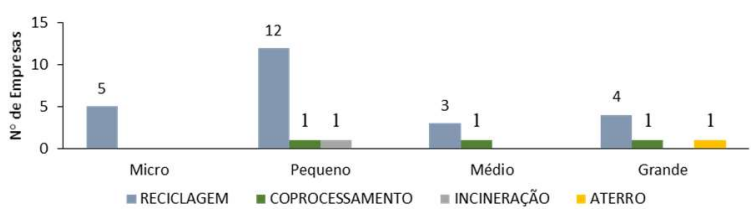

Figura 2: Porte das empresas avaliadas.

Figura 1: Formas de tratamento dos resíduos Classe I.

A partir da Figura 3 pode-se verificar a destinação final dada aos resíduos gerados.

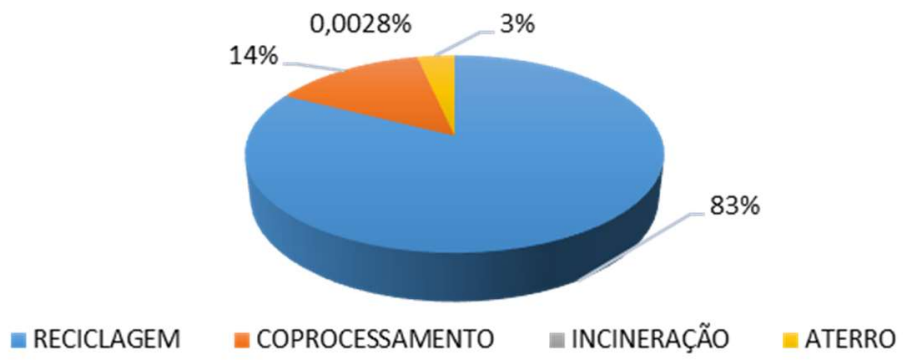

Figura 3: Tipo de tratamento dos resíduos.

Ao se analisar o montante dos resíduos tratados por tipo de tratamento, no período de 24 meses, verificou-se que as empresas de reciclagem tratam $83 \%$ de todos os resíduos produzidos pela empresa geradora de resíduos, ou seja, (46.646 t); já as empresas de coprocessamento, 14\%, (7.890 t); a de aterro, $3 \%,(1.945 \mathrm{t})$ e a empresa de incineração, $0,0028 \%(1,6 \mathrm{t})$.

\section{Auditoria ambiental de homologação}

A escolha dos quesitos auditados e a sua relação com os instrumentos legais, estão em conformidade as considerações de Vieira (2011) pois consistem em um processo sistemático de inspeção dos riscos ambientais, legislação ambiental e a sua importância junto à comunidade e órgão ambiental. 0 quadro 1 descreve os quesitos avaliados durante as auditorias de homologação, sua importância, relação com os instrumentos legais aplicáveis e com as políticas ambientais nacionais.

Dentre os quesitos auditados destacam-se: Os quesitos $n^{\circ} 1$ e 2 , licenciamento ambiental e suas condicionantes foram relacionados conforme a Resolução do Conselho Nacional do Meio Ambiente CONAMA n 381/2006 e apoiadas no instrumento IV da Política Nacional do Meio Ambiente - PNMA, que trata do licenciamento ambiental, levando-se em consideração a Resolução do CONAMA n 237/1997 e Portaria do Instituto Ambiental do Paraná - IAP n²24/2007 que dispõem sobre aspectos do licenciamento ambiental; Para a justificativa legal relacionada ao cadastro técnico federal, o quesito $n^{\circ} 3$ auditado foi elaborado com base nos instrumentos VIII e XII da PNMA. A legislação relacionada a estes dois instrumentos (VIII e XII) incluem ainda a Instrução Normativa $n^{\circ}$ 006/2013 e a Instrução Normativa $n^{\circ}$ 010/2013 do Instituto Brasileiro do Meio Ambiente e dos Recursos Naturais Renováveis - IBAMA (2013a; 2013b), que 
Análise de resultados de auditorias ambientais de homologação de empresas de tratamento de resíduos sólidos, provenientes de uma indústria automobilística

regulamentam o Cadastro Técnico Federal/Atividades Potencialmente Poluidoras - CTF/APP e o Cadastro Técnico Federal/Instrumentos de Defesa Ambiental CTF/AIDA, respectivamente; A outorga de uso da água, quesito $n^{\circ} 4$, foi suportada pela Política Nacional de Recursos Hídricos - PNRH no que se refere à cobrança pelo uso das águas, pelo instrumento XIII da PNMA e pela Lei Federal $n^{\circ}$ 9.984/2000 que atribui Agência Nacional das Águas - ANA a responsabilidade em autorizar o direito ao uso de recursos hídricos de domínio da União; Os quesitos de Alvará emitido pelo Corpo de Bombeiros e Prefeitura, quesitos $n^{\circ} 5$ e 9 , foram fundamentados pelo Estatuto das Cidades, nas suas Diretrizes Gerais e Instrumentos da Política Urbana; Já os quesitos 6, 7 e 8, produtos controlados pelo Exército, segundo descrito no Decreto $n^{\circ} 3.665 / 2000$, Polícia Federal e Polícia Civil estão relacionados à PNMA (Instrumento IX) quando esta estabelece que a produção, fabricação e uso de produtos químicos está associada às atividades potencialmente poluidoras e comercializar ou estocar produtos nocivos, tóxicos ou perigosos sem autorização é considerado crime; 0 Estatuto das Cidades fundamentou o quesito n 9, assim como a Lei 11.095/2004; A criação de um SGA, quesito $n^{\circ} 10$, é incentivada pelo Instrumento $V$ da PNMA, quando sugere a redução de impactos ambientais das organizações; Os quesitos $n^{\circ} 11$ e 16 foram fomentados pela Lei $n^{\circ} 12.305 / 2010$, que estabeleceu a PNRS e serviu de apoio para a definição dos quesitos associados ao PGRS e ao Inventário de Resíduos Sólidos, além da Resolução CONAMA n 313/2002, que dispõe sobre o Inventário Nacional de Resíduos Sólidos Industriais; Os padrões de qualidade do solo e águas subterrâneas, quesito $n^{\circ} 12$, determinados pela Resolução do CONAMA $n^{\circ}$ 420/2009, foram relacionados com o Instrumento I da PNMA; O instrumento I da PNMA descreve os padrões de qualidade ambiental e a Política Nacional de Resíduos Sólidos - PNRH faz o enquadramento dos corpos de água em classe, segundo seu uso. Nestes instrumentos foram analisados os padrões de lançamento de efluentes industriais, fundamentados pela Resolução do CONAMA n 357/2005 e $n^{\circ} 430 / 2011$, que classifica os corpos de água e estabelece condições e padrões de lançamento de efluentes, quesito $n^{\circ} 13$; O quesito $n^{\circ} 14$, declaração de carga poluidora, parte integrante do instrumento I da PNMA e da PNRH, foi estabelecido pela Resolução do CONAMA n 430/2011 e pela Portaria do IAP n 150/2013, que define os critérios e exigências para a apresentação da declaração de carga poluidora no Estado do Paraná; A avaliação do quesito $n^{\circ} 15$, emissões atmosféricas, foi amparada pelo instrumento I da PNMA (padrões de qualidade ambiental) e na Lei $n^{\circ} 12.187 / 2009$, PNMC. Para tanto, seguiu-se também a Resolução da SEMA $n^{\circ}$ 16/2014, que define critérios para o controle da qualidade do ar e a PNMC; O controle da qualidade do ar, ruído, quesito $n^{\circ}$ 17, foi explanado pela Resolução do CONAMA n 001/1990 que dispões sobre critérios e emissões de ruídos e definido pelo instrumento I da Política Nacional de Mudanças Climáticas - PNMA; O cadastro junto a ANP, quesito $n^{\circ} 18$, foi relacionado com a Resolução do CONAMA n³63/2005, Portaria da ANP n 19/2009 e com a PNRS quando esta determina o rerrefino para o óleo lubrificante (ANP, 2009).

A escolha dos quesitos auditados e sua relação com os instrumentos legais também estão de acordo com as considerações de Vieira (2011) pois estas consistem em um processo sistemático de inspeção dos riscos ambientais, legislação ambiental e a sua importância junto à comunidade e ao órgão ambiental. 
Quadro 1: Quesitos auditados nas empresas avaliadas.

\begin{tabular}{|c|c|c|c|c|}
\hline $\mathbf{N}^{\circ}$ & QUESITOS AUDITADOS & IMPORTÂNCIA & INSTRUMENTOS LEGAIS VIGENTES & $\begin{array}{c}\text { INSTRUMENTOS DAS } \\
\text { POLITICAS NACIONAIS }\end{array}$ \\
\hline 1 & $\begin{array}{l}\text { A empresa possui Licença de Operação ou dispensa de Licença relativa à } \\
\text { sua atividade? }\end{array}$ & $\begin{array}{l}\begin{array}{l}\text { Garantir que empreendimentos não danifiquem ecossistemas, que sejam de conhecimento dos órgãos } \\
\text { ambientias. }\end{array} \\
\end{array}$ & $\begin{array}{l}\text { a) Resolução CONAMA n'237/1997 } \\
\text { b) Portaria IAP n'224/2005 }\end{array}$ & IV - PNMA \\
\hline 2 & As condicionantes da licença ambiental estão sendo cumpridas? & Garantir que suas atividades estejam vinculadas ao cumprimento dos requisitos legais. & a) Resolução CONAMA nº 381/2006 & IV-PNMA \\
\hline 3 & $\begin{array}{l}\text { A empresa possui o CTF-Cadastro Técnico Federal relativo às atividades } \\
\text { potencialmente poluidoras? }\end{array}$ & Tornar de conhecimento do Estado as atividades poluidoras exercídas pelas organizações. & $\begin{array}{l}\text { a) Lei nº.938, de } 1981 \\
\text { b) Instrução Normativa IBAMA no006/2013 } \\
\text { c) Instrução Normativa IBAMA nº10/2013 }\end{array}$ & VIII e XII - PNMA \\
\hline 4 & $\begin{array}{l}\text { A empresa possui outorga para captação de água subterrânea e/ou } \\
\text { lançamento de efluente? }\end{array}$ & Evitar o uso de água de forma irracional, impedir a escasseze impactos ambientais. & Lei Federal $\mathrm{n}^{\circ} 9.984 / 2000$ & XIII - PNMA e PNRH \\
\hline 5 & Possui Auto de vistoria do corpo de bombeiros? & Comprovar a estabilidade dos edificios em caso de incêndio e preservar a vida. & $\begin{array}{l}\text { Decreto Lei no } 13.976 / 2002 \text { e complementada } \\
\text { pela Lei 14.278/2004 }\end{array}$ & $\begin{array}{c}\text { ESTATUTO DAS } \\
\text { CIDADES }\end{array}$ \\
\hline 6 & $\begin{array}{l}\text { A empresa possui o Certificado de registro do exército para produtos } \\
\text { controlados? }\end{array}$ & $\begin{array}{l}\text { Impedir o uso de produtos químicos em confecção de armamento bélico de forma ilicita. Garantir a } \\
\text { segurança nacional. }\end{array}$ & Decreto n $3.665 / 2000$ & IX - PNMA \\
\hline 7 & $\begin{array}{l}\text { Possui Certificado de registro de fincionamento, emitido pela Policia } \\
\text { Federal para produtos controlados? }\end{array}$ & Impedir o uso de produtos químicos no uso de entorpecentes. Garantir a saúde da população. & $\begin{array}{l}\text { a) Portaria Min. n`1.274 } \\
\text { b) Lei n¹0.357/2001 }\end{array}$ & IX - PNMA \\
\hline 8 & $\begin{array}{l}\text { A empresa possui Alvaŕ? A Licença foi emitida pela Policia Civil para } \\
\text { produtos controlados? }\end{array}$ & $\begin{array}{l}\text { Fiscalizar o uso do consumo de produtos controlados pelo Exercito e Policia Federal e outros } \\
\text { especificos de cada estado. }\end{array}$ & Portaria no $005 / 2013$ & IX - PNMA \\
\hline 9 & A empresa possui Alvará Municipal? & $\begin{array}{l}\text { Garantir que o estabelecimento esteja em conformidade com as leis de zoneamento, evitando assim, } \\
\text { construçôes irregulares que prejudiquem a sociedade como um todo. }\end{array}$ & Lein ${ }^{\circ} 11.095 / 2004$ & $\begin{array}{l}\text { ESTATUTO DAS } \\
\text { CIDADES }\end{array}$ \\
\hline & A empresa possui um Sistema de Gestão implantado ou certificado? & Assegurar que as empresas possuam rotinas estabelecida para controlar os seus impactos ambientais. & Lein $9.605 / 1998$ & V-PNMA \\
\hline 11 & $\begin{array}{l}\text { A empresa acondiciona de forma adequada seus residuos perigosos e não } \\
\text { perigosos corretamente? }\end{array}$ & Evitar a contaminação do solo e água, prejudicando assima a saude pública e ambiental. & a) NBR 12.235 e b) NBR 11.174 & PNRS \\
\hline & $\begin{array}{l}\text { A empresa realiza análises e caracterização da qualidade do solo e das } \\
\text { águas subterrâneas? Há alguma exigêncí ou condicionante do órgão } \\
\text { ambiental? }\end{array}$ & $\begin{array}{l}\text { Prevenir a contaminação do solo em empresas que exerçam atividades potencialmente poluidoras. } \\
\text { Controlar a qualidade das águas subterrâneas e garantir a saúde pública. }\end{array}$ & Resolução CONAMA n̊420/2009 & I- PNMA \\
\hline 13 & $\begin{array}{l}\text { Os efluentes domésticos e/ou industriais tratados quando lançados em corpo } \\
\text { receptor, atendem aos padróes definidos pela legislaçẫo local ap licável? }\end{array}$ & Assegurar e controlar a qualidade da água para evitar problemas ambientais e de saúde pública. & $\begin{array}{l}\text { a) Resolução CONAMA ñ577/2005 } \\
\text { b) Resolução CONAMA n430/2011 }\end{array}$ & I - PNMA e PNRH \\
\hline 14 & $\begin{array}{l}\text { A empresa possui Dechracãa de Carga Poluidora protocolada junto ao } \\
\text { órgão ambiental? }\end{array}$ & $\begin{array}{l}\text { Controlar os poluentes descartados nos corpos receptores. Controlar a qualidade dos copros hídricos } \mathrm{e} \\
\text { garantir a saúde pública. }\end{array}$ & $\begin{array}{l}\text { a) Resolucão } \mathrm{CONAMA} \mathrm{n}^{\circ} 430 / 2011 \\
\text { b) Portaria IAP n } 150 / 2013\end{array}$ & I - PNMA e PNRH \\
\hline 5 & $\begin{array}{l}\text { Existem análises das emissões atmosféricas quando exigido como } \\
\text { condicionante de licenciamento? }\end{array}$ & Assegurar e controlar a qualidade do ar para evitar problemas ambientais e de saúde pública. & Resolução SEMA ño16/2014 & I - PNMA e PNMC \\
\hline 16 & $\begin{array}{l}\text { A empresa protocolou o Inventário de Resíduos e PGRS junto ao órgão de } \\
\text { controle ambiental? }\end{array}$ & $\begin{array}{l}\text { Controlar a gestão dos residuos sólidos gerados pelas organizaç̃es afim de garantir o seu correto } \\
\text { tratamento, evitando impactos ambientais e risco a saúde pública. }\end{array}$ & $\begin{array}{l}\text { a) PNRS - Lei n } 12.305 / 2010 \\
\text { b) Resolução CONAMA n³13/2002 }\end{array}$ & PNRS \\
\hline & $\begin{array}{l}\text { Existe análise de rúido no entorno da empresa quando exigido como } \\
\text { condicionante de licenciamento? }\end{array}$ & $\begin{array}{l}\text { Evitar que ruídos acima dos permitidos possam afugentar espécies animais importantes para a } \\
\text { manutenção dos ecosistemas ambientais. }\end{array}$ & $\begin{array}{l}\text { a) NBR } 10.151 \\
\text { b) Resolução CONAMA ño01/90 }\end{array}$ & IV - PNMA \\
\hline & $\begin{array}{l}\text { A empresa encontra-se cadastrada junto à ANP para as atividades de } \\
\text { rerrefino e coleta de óleo lubrificante usado? }\end{array}$ & Controlar os produtores de rerrefino e garantir a qualidade do óleo usado. & $\begin{array}{l}\text { a) Resolução CONAMA n³62/2005 } \\
\text { b) ANP 19/2009 }\end{array}$ & PNRS \\
\hline
\end{tabular}

\section{Verificação dos resultados obtidos nas auditorias ambientais de homologação}

A verificação dos resultados avaliados levou em consideração a quantidade de quesitos auditados e o seu percentual de atendimento legal, como apresentado na figura 4. Dos 12 quesitos avaliados e aplicáveis à empresa de aterro, 2 atingiram valores de até $60 \%$ do atendimento legal, representando alto risco ambiental para a empresa geradora de resíduos (avaliação de solo e água subterrânea e análise de efluentes) e 10 obtiveram resultados superiores a 80\%, considerado como de baixo risco ambiental.

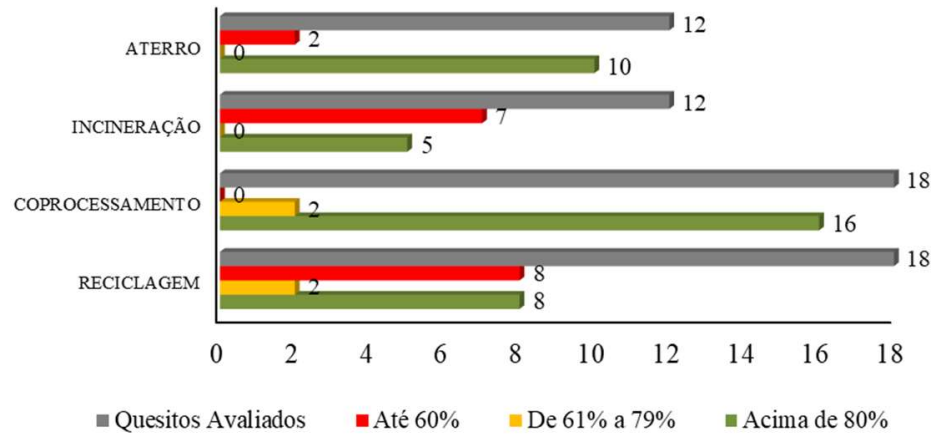

Figura 4: Verificação dos resultados por quesitos avaliados.

Já para a empresa de incineração, dos 12 quesitos avaliados, 7 resultaram em valores de até $60 \%$ de atendimento (condicionantes da licença de operação, cadastro técnico federal, implantação de um sistema de gestão ambiental, armazenamento de resíduos, avaliação de solo e água subterrânea, inventário de resíduos sólidos e análise de ruído), ou seja, considerado como de alto risco ambiental e apenas 5 quesitos tiveram atendimento legal igual ou superior a $80 \%$, de baixo risco ambiental.

Dos 18 quesitos avaliados para as empresas de coprocessamento, 16 apresentaram valores superiores a $80 \%$ de atendimento legal, ou seja, baixo risco ambiental e 2 quesitos, dos 18 auditados, apresentaram valores entre 61 e 79\% (avaliação de solo e água subterrânea e armazenamento de resíduos), 
representando um risco médio ambiental para a empresa geradora de resíduos.

Para as empresas de reciclagem observou-se que dos 18 quesitos auditados, 8 apresentaram resultados com valores de até $60 \%$ de atendimento, considerados de alto risco ambiental (certificado de registro no exército, implantação de um sistema de gestão ambiental, avaliação de solo e água subterrânea, análise de efluentes, declaração de carga poluidora, inventário de resíduos sólidos e análise de ruído), 8 acima dos $80 \%$, baixo risco ambiental e finalmente, 2 entre 61 e $79 \%$, ou seja, médio risco ambiental (auto de vistoria do corpo de bombeiros e análises de emissões atmosféricas).

\section{Avaliação dos resultados de homologação nos diferentes processos de tratamento}

Para as empresas cujo tratamento foi a reciclagem $64 \%$ estavam em conformidade com a legislação vigente, apresentando um risco ambiental médio (resultados entre $61 \%$ a $79 \%$ de atendimento legal), como apresentado no (Quadro 2).

Quadro 2: Avaliação dos resultados das auditorias.

\begin{tabular}{|c|c|c|c|c|c|c|c|}
\hline $\mathbf{N}^{\circ}$ & QUESITOS AUDITADOS & LEGISLAÇ̃̃̃O ANALISADA & RECICLAGEM & \begin{tabular}{|c|} 
CO- \\
PROCESSAMENTO \\
\end{tabular} & INCINERAÇÃO & ATERRO & MÉDIA FINAL \\
\hline 1 & LICENÇA DE OPERAÇ̃̃o & $\begin{array}{l}\text { a) Resolução CONAMA n 237/1997 } \\
\text { b) Portaria IAP nº 224/2005 }\end{array}$ & $100 \%$ & $100 \%$ & $100 \%$ & $100 \%$ & $100 \%$ \\
\hline 2 & $\begin{array}{c}\text { CONDICIONANTES DA LICENÇA DE } \\
\text { OPERAÇÃOO } \\
\end{array}$ & a) Resolução CONAMA nº 381/2006 & $90 \%$ & $83 \%$ & $50 \%$ & $100 \%$ & $81 \%$ \\
\hline 3 & CADASTRO TÉCNICO FEDERAL & $\begin{array}{l}\text { a) Instrução Normativa IBAMA 006/2013 } \\
\text { b) Instrução Normativa IBAMA 010//2013 }\end{array}$ & $83 \%$ & $100 \%$ & $50 \%$ & $100 \%$ & $83 \%$ \\
\hline 4 & OUTORGA DE USO DA ÁGUA & Lei Federal $\mathrm{n}^{\circ} 9.984 / 2000$ & $100 \%$ & $100 \%$ & NA & NA & $100 \%$ \\
\hline 5 & $\begin{array}{l}\text { ALVARÁ DE VISTORIA DO CORPO DE } \\
\text { BOMBEIROS }\end{array}$ & Decreto Lei n ${ }^{\circ}$ 13.976/2002 e complementada pela Lei 14.278/2004 & $73 \%$ & $100 \%$ & $100 \%$ & $100 \%$ & $93 \%$ \\
\hline 6 & $\begin{array}{l}\text { CERTIFICADO DE REGULARIDADE DO } \\
\text { EXÉRCITO }\end{array}$ & Decreto $\mathrm{n}^{\circ} 3.665 / 2000$ & $42 \%$ & $100 \%$ & NA & NA & $71 \%$ \\
\hline 7 & $\begin{array}{l}\text { CERTIFICADO DE REGULARIDADE DA } \\
\text { POLÍCIA FEDERAL }\end{array}$ & $\begin{array}{l}\text { a) Portaria Min. } \mathrm{n}^{\circ} 1.274 \\
\text { b) Lei n }{ }^{\circ} 10.357 / 2001\end{array}$ & $100 \%$ & $100 \%$ & NA & NA & $100 \%$ \\
\hline 8 & $\begin{array}{l}\text { CERTIFICADO DE REGULARIDADE DA } \\
\text { POLÍCIA CIVIIL } \\
\end{array}$ & Portaria $\mathrm{n}^{\circ}$ 005/2013 & $100 \%$ & $100 \%$ & NA & NA & $100 \%$ \\
\hline 9 & ALVARÁ DE FUNCIONAMENTO & Lein ${ }^{\circ} 11.095 / 2004$ & $98 \%$ & $100 \%$ & $100 \%$ & $100 \%$ & $100 \%$ \\
\hline 10 & SISTEMA DE GESTÃO AMBIENTAL & Lei n ${ }^{\circ} 9.605 / 1998$ & $42 \%$ & $100 \%$ & $0 \%$ & $100 \%$ & $61 \%$ \\
\hline 11 & ARMAZENAMENTO DE RESÍDUOS & $\begin{array}{l}\text { a) NBR } 12.235 \\
\text { b) NBR } 11.174\end{array}$ & $88 \%$ & $67 \%$ & $0 \%$ & $100 \%$ & $64 \%$ \\
\hline 12 & SOLO E ÁGUA SUBTERRÂNEA & Resolução CONAMA n'420/2009 & $17 \%$ & $67 \%$ & $50 \%$ & $50 \%$ & $46 \%$ \\
\hline 13 & EFLUENTES INDUSTRIAIS & $\begin{array}{l}\text { a) Resolução CONAMA n }{ }^{\circ} 357 / 2005 \\
\text { b) Resolução CONAMA n' } 430 / 2011\end{array}$ & $27 \%$ & $100 \%$ & $100 \%$ & $50 \%$ & $69 \%$ \\
\hline 14 & DECLARAÇÃO DE CARGA POLUIDORA & $\begin{array}{l}\text { a) Resolução CONAMA no } 430 / 2011 \\
\text { b) Portaria IAP n }{ }^{\circ} 150 / 2013\end{array}$ & $18 \%$ & $100 \%$ & NA & $100 \%$ & $73 \%$ \\
\hline 15 & EMISSÕES ATMOSFÉRICAS & Resolução SEMA ñ 016/2014 & $63 \%$ & $100 \%$ & $100 \%$ & $100 \%$ & $91 \%$ \\
\hline 16 & $\begin{array}{c}\text { INVENTÁRIO DE RESÍDUOS SÓLIDOS E } \\
\text { PLANO DE GERENCIAMENTO DE } \\
\text { RESÍDUOS SÓLIDOS } \\
\end{array}$ & $\begin{array}{l}\text { a) PNRS - Lei no } 12.305 \text {, de 2/08/2010 } \\
\text { b) Resolução CONAMA n }{ }^{\circ} 313 / 2002\end{array}$ & $35 \%$ & $100 \%$ & $50 \%$ & NA & $62 \%$ \\
\hline 17 & RUIDO & $\begin{array}{l}\text { a) NBR } 10.151 \\
\text { b) Resolução CONAMA n } 001 / 90\end{array}$ & $31 \%$ & $100 \%$ & $0 \%$ & $100 \%$ & $58 \%$ \\
\hline \multirow[t]{3}{*}{18} & $\begin{array}{c}\text { RERREFINO - AGÊNCIA NACIONAL DO } \\
\text { PETRÓLEO } \\
\end{array}$ & $\begin{array}{l}\text { a) Resolução CONAMA no 362/2005 } \\
\text { b) ANP n }{ }^{\circ} \text { 19/2009 }\end{array}$ & $50 \%$ & NA & NA & NA & $50 \%$ \\
\hline & & MÉDIA GERAL & $64 \%$ & $95 \%$ & $58 \%$ & $92 \%$ & \\
\hline & & LEGENDA & $<60 \%$ & $61 \%-79 \%$ & $>80 \%$ & & \\
\hline
\end{tabular}

Tanto as empresas de coprocessamento, com 95\% de atendimento legal, quanto a empresa de aterro com 92\%, apresentaram baixo risco ambiental para a empresa geradora de resíduos, levando em consideração que o risco ambiental baixo representa resultados acima de $80 \%$ de atendimento.

As empresas de coprocessamento (pequeno, médio e grande porte) e de disposição em aterro (grande porte), mostraram-se ser as mais seguras para a empresa geradora de resíduos, considerando os aspectos legais ambientais avaliados na auditoria.

As quantidades de resíduos tratados pelas empresas de coprocessamento e aterro, corresponderam a 75\% (7.890 toneladas tratadas pelas empresas de coprocessamento e 1.945 toneladas de resíduos destinados a aterro) dos resíduos Classe I, porém, observou-se que grande parte dos resíduos com alto risco e criticidade ambiental, foram destinados às empresas consideradas de baixo risco ambiental, uma vez que 
estas empresas recebem fiscalizações frequentes do órgão ambiental competente, além de possuírem sistema de gestão ambiental certificado, executarem auditorias internas e possuírem melhor estrutura técnico-financeira para promoverem as devidas adequações e melhorias contínuas de seus processos.

Por sua vez, a empresa de incineração apresentou o menor resultado avaliado, sendo este de $58 \%$ de atendimento legal, ou seja, um alto risco ambiental para a empresa geradora de resíduos. Observou-se, ainda, que a empresa de incineração não possuía nenhum sistema de auto avaliação, auditoria ambiental, ou de sistema de gestão ambiental implantado ou certificado na empresa, no momento da auditoria.

Mesmo sendo as empresas de Coprocessamento e Aterro as que apresentaram os mais baixos riscos ambientais, observa-se que há uma tendência nas indústrias, sob o ponto de vista econômico e sustentável, de promover a reciclagem como forma de atendimento a política nacional de resíduos sólidos, sendo estas empresas as que apresentaram o maior número de quesitos não conformes avaliados, (10 quesitos, de um total de 18).

A avaliação dos quesitos não conformes apresentados a seguir, estão em concordância com Vélez et al. (2017) pois resultam em uma maneira de identificar as áreas ambientalmente vulneráveis de um processo ou serviço a fim de determinar a conformidade com os padrões do sistema de gerenciamento, legislações ambientais e políticas ambientais e podem ser observados na figura 5 , que ilustra a relação dos quesitos avaliados nas empresas de reciclagem e o seu percentual de atendimento legal.

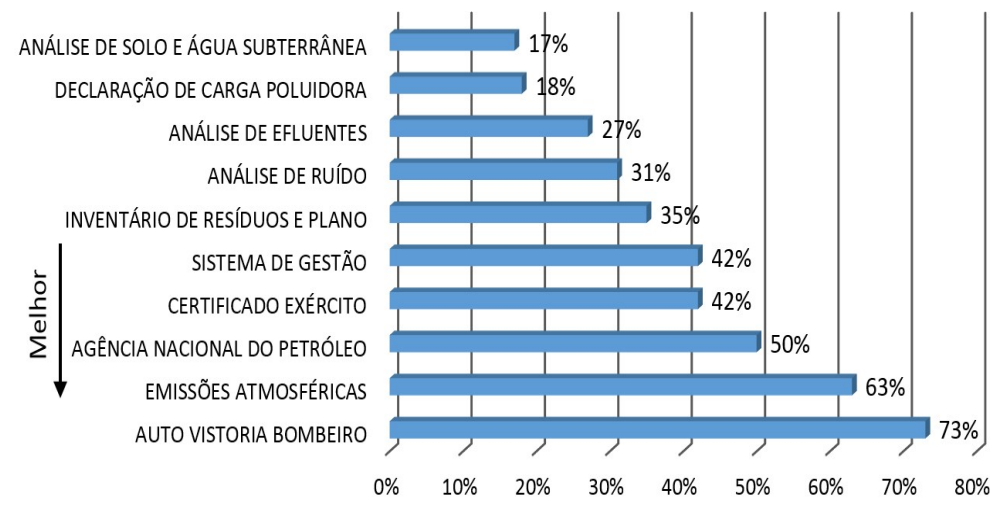

Figura 5: Quesitos críticos das empresas de reciclagem.

Conforme descrito na figura 5 a legislação aplicada às empresas de reciclagem com resultado mais desfavorável foi a Resolução do CONAMA n 420/2009 que trata sobre parâmetros da qualidade do solo e de água subterrânea, apenas $17 \%$ das empresas de reciclagem, cujo quesito era aplicado, monitoravam a qualidade do solo e da água subterrânea.

As auditorias realizadas demostraram que, as empresas de reciclagem desconheciam quais os parâmetros deveriam seguir para a realização das análises de investigação citada na Resolução do CONAMA $n^{\circ} 420 / 2009$, portanto a auditoria ambiental de homologação, além de outros objetivos, apresentou resultados práticos de controle e educação ambiental.

A declaração de carga poluidora foi realizada por apenas 18\% (dezoito por cento) das empresas analisadas cujo quesito era aplicável. A maioria destas empresas se encontraram em desacordo com o art. 
Análise de resultados de auditorias ambientais de homologação de empresas de tratamento de resíduos sólidos, provenientes de uma indústria

28, da Resolução do CONAMA n 430/2011, determina que o responsável por fonte potencial ou efetivamente poluidora de recursos hídricos, deve apresentar ao órgão ambiental, até o dia 31 de março de cada ano, a declaração de carga poluidora.

Tanto o controle de monitoramento de solo, quanto a obtenção da declaração de carga poluidora foram os quesitos mais críticos quanto a aplicação dos requisitos legais pertinentes. As empresas de coprocessamento por sua vez, tiveram dois quesitos auditados não atendidos integralmente: o de armazenamento de resíduos perigosos e o de controle e monitoramento do solo, para estes dois parâmetros, o atendimento legal foi de $67 \%$, estando os demais quesitos em conformidade legal.

Para a empresa de incineração, durante a auditoria ambiental verificou-se que, dos quesitos auditados, 4 foram atendidos parcialmente, $50 \%$ e três quesitos não foram atendidos completamente, resultando em $0 \%$ de atendimento (Figura 6 ).

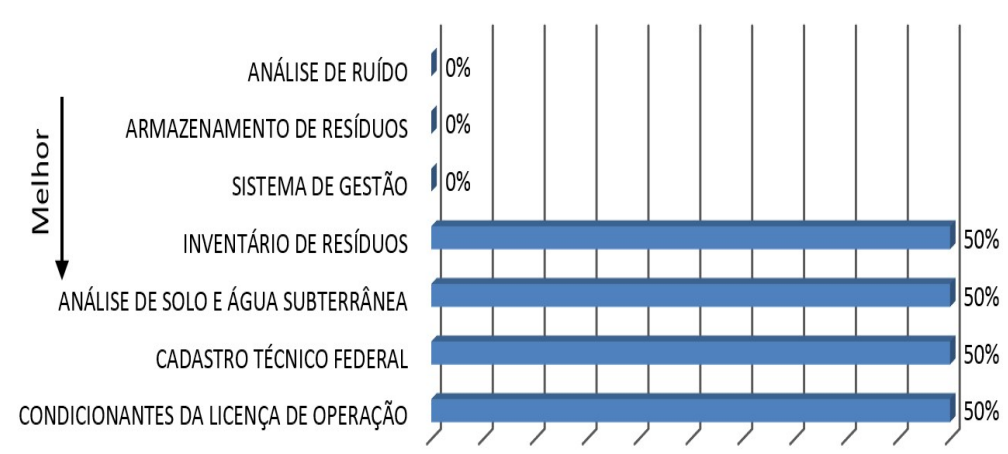

$\begin{array}{lllllllllll}\% \text { de atendimento legal } 0 \% & 5 \% & 10 \% & 15 \% & 20 \% & 25 \% & 30 \% & 35 \% & 40 \% & 45 \% & 50 \%\end{array}$

Figura 6: Quesitos críticos das empresas de incineração.

Durante a auditoria ambiental de homologação na empresa de aterro verificou-se que, dos quesitos auditados, somente dois quesitos tiveram o atendimento de 50\%, segundo as exigências legais: análise de solo e de água subterrânea e de efluentes industriais, estando os demais quesitos em conformidade legal.

\section{CONCLUSÕES}

A partir dos resultados das auditorias ambientais de homologação realizadas pode-se concluir que a maior parte das empresas de tratamento de resíduos sólidos que prestaram serviços a Industria Automobilística avaliada neste estudo, estão localizadas no estado do Paraná, na Região Metropolitana de Curitiba, como esperado, isto se deve a maior facilidade de transporte dos resíduos, bem como disponibilidade de áreas para o armazenamento e tratamento dos resíduos.

Das 24 empresas auditadas de reciclagem 12 foram consideradas de pequeno porte, isto se deve ao fato de que empresas de pequeno porte são mais comuns no segmento de reciclagem e estão em ascendência no mercado, devido aos programas de sustentabilidade exigidos pelos órgãos ambientais, acordos internacionais e posicionamento do consumidor.

Do ponto de vista das auditorias ambientais de homologação, as empresas de grande porte, independente do seu tipo de tratamento, apresentaram os melhores resultados no que diz respeito ao 
atendimento legal, isto se deve ao fato de empresas de grande porte possuírem sistemas próprios de gestão ambiental, terem planos sólidos de auditorias internas e passarem por fiscalizações frequentes dos órgãos ambientais.

Dos resíduos tratados, $83 \%$ do montante gerado pela empresa geradora de resíduos sólidos foram destinados à reciclagem, isto se dá a grande quantidade de resíduos metálicos (chapas) e resíduos de madeira gerada pela indústria automobilística.

A empresa de tratamento de resíduos que apresentou maior risco ambiental à empresa geradora de resíduos sólidos, foi a empresa de incineração, com $58 \%$ dos requisitos legais aplicáveis atendidos, seguida da empresa de reciclagem, que obteve $64 \%$ de atendimento aos quesitos avaliados, ambas de pequeno porte. Este resultado é devido pela falta de controle dos requisitos legais aplicáveis às suas atividades, ausência de um programa coeso de gestão ambiental e auditorias.

As empresas de coprocessamento tiveram o maior número de quesitos auditados conformes: 18 quesitos auditados, apenas 2 apresentaram resultados de 67\% de atendimento parcial legal: "Análise de Solo e Água Subterrânea" e "Armazenamento de Resíduos Perigosos". Isto se deve aos controles ambientais, sistema de gestão implantado e certificado, as fiscalizações e auditorias frequente realizadas. São também empresas de grande porte, com recurso disponíveis para a rápida adequação e controle ambiental.

O quesito de maior criticidade e comum a todos os tipos de empresas auditadas foi "Análise de Solo e Água Subterrânea" sendo $17 \%$ de atendimento legal nas empresas de reciclagem, 50\% nas de incineração e aterro e $67 \%$ nas empresas de coprocessamento, devido ao fato da legislação aplicada, ser uma normativa relativamente nova, são poucas vezes foram citados na licença de operação das empresas avaliadas. Outro fator observado para este quesito não ser plenamente atendido, foi a interpretação da legislação quanto a obrigatoriedade do atendimento e seus parâmetros.

Os quesitos avaliados podem ser reproduzidos a outros tipos de auditorias ambientais, não somente as de homologação de empresas de tratamento de resíduos industriais, pois foram fundamentados nas políticas ambientais brasileiras e nos instrumentos ambientais vigentes aplicados a todo o território nacional.

\section{REFERÊNCIAS}

ABNT. Associação Brasileira de Normas Técnicas. NBR 10.004: classificação de resíduos. Rio de Janeiro: ABNT, 2004.

ANP. Agencia Nacional do Petróleo. Portaria ANP $n^{\circ} 19$ de 18 de junho de 2009. Dispõe sobre autorização para atividade de rerrefino de óleo lubrificante usado ou contaminado, 2009.

BRASIL. CONAMA n ${ }^{\circ} 313$ de 29 de outubro de 2002. Dispõe sobre o Inventário Nacional de Resíduos Sólidos Industriais. Brasília: DOU, 2002.

BRASIL. Lei $\mathrm{n}^{\circ}$ 12.187, de 29 de dezembro de 2009. Institui a Política Nacional sobre Mudanças Climáticas, Brasília: DOU, 2009.
BRASIL. Lei $\mathbf{n}^{\circ} \mathbf{1 2 . 3 0 5}$, de $\mathbf{2}$ de agosto de 2010. Institui a Política Nacional de Resíduos Sólido, Brasília, 2010.

BRASIL. Lei $\mathbf{n}^{\circ} \mathbf{3 . 6 6 5}$, de 20 de novembro de 2000. Dá nova redação ao Regulamento para a Fiscalização de Produtos Controlados (R-105). Brasília: DOU, 2000.

BRASIL. Lei $n^{\circ}$ 9.433, de 08 de janeiro de 1997. Institui a Política Nacional de Recursos Hídricos e dá outras providências. Brasília: DOU, 1997.

BRASIL. Lei $\mathbf{n}^{\circ} \mathbf{9 . 9 8 4}$ de $\mathbf{1 7}$ de julho de $\mathbf{2 0 0 0}$. Dispõe sobre a criação da Agência Nacional de Águas - ANA. Brasília: ANA, 2000.

BRASIL. Lei no 6.938, de 31 de agosto de 1981 . Política Nacional do Meio Ambiente. Brasília: DOU, 1981. 
BRASIL. Ministério do Estado da Justiça. Portaria 1.274 de 25 de agosto de 2003. Dispões sobre o controle de uso dos produtos químicos controlados pela Polícia Federal. Brasília, 2003.

BRASIL. Resolução CONAMA no 237 de 19 de dezembro de 1997. Dispõe sobre o Licenciamento Ambiental. 1997. Publicação DOU no 247, de 22 de dez. 1997, p. 30.84130.843, 1997.

\section{BRASIL. Resolução CONAMA no $\mathbf{3 5 7}$ de $\mathbf{1 7}$ de março de} 2005. Classificação dos corpos de água e padrões de lançamento de efluentes. Brasília: DOU, 2005.

BRASIL. Resolução CONAMA no 381 de 14 de dezembro de 2006. Requisitos mínimos para a realização de auditoria ambiental. Brasília: DOU, 2006.

BRASIL. Resolução CONAMA no $\mathbf{4 2 0}$ de $\mathbf{2 8}$ de dezembro de 2009. Dispõe sobre valores orientadores de qualidade do solo e água subterrânea quanto à presença de substâncias químicas. Brasília: DOU, 2009.

BRASIL. Resolução CONAMA no $\mathbf{4 3 0}$ de $\mathbf{1 3}$ de maio de 2011. Condições e padrões de lançamento de efluentes. Brasília: DOU, 2011.

CÓRDOVA, R.; GUILHERMO, R.. Fundamentos básicos para la ejecución de la auditoría ambiental. Revista Centro de Información y Gestión Tecnológica, Holguín-Cuba, v.22, n.1, 2016.

IBAMA. Instituto Brasileiro do Meio Ambiente e dos Recursos Hídricos. Instrução normativa no $\mathbf{6}$ de $\mathbf{1 5}$ de março de 2013. Regulamenta o Cadastro Técnico Federal de Atividades Potencialmente Poluidoras e Utilizadoras de Recursos Ambientais. Brasília: IBAMA, 2013a.

IBAMA. Instituto Brasileiro do Meio Ambiente e dos Recursos Hídricos, IBAMA. Instrução normativa no 10, de 27 de maio de 2013. Regulamenta o Cadastro Técnico Federal de Atividades e Instrumentos de Defesa Ambiental. Brasília: IBAMA, 2013b.

INGOLE, S. P.. Environmental Auditing: Its Benefits and Counterance. International Journal of Science Innovationsand Discoveries, v.2, n.2, p.152-156, 2012.
MOREIRA, A. L.; BARAN, K. P.. A Importância da Auditoria Interna para as Organizações. Revista Científica Multidisciplinar Núcleo do Conhecimento, v.5, n.2, p.84-98, 2018.

PARANÁ. Instituto Ambiental do Paraná. Portaria IAP n 224 de 05 de dezembro de 2007. Licenciamento Ambiental. IAP, 2007.

PARANÁ. Instituto Ambiental do Paraná, IAP. Portaria nº 150 de 16 de maio de 2013. Estabelece os critérios e exigências para a Declaração de Carga poluidora. 2013.

PARANÁ. Secretaria Especial de Meio Ambiente. Resolução no 016 de 15 de abril de 2014. Define critérios para o Controle da Qualidade do Ar como um dos instrumentos básicos da gestão ambiental. SEMA, 2014.

QUEIROZ, J. A. A.. A Auditoria Ambiental como Ferramenta de Desenvolvimento Sustentável das Cidades Amazônicas Submetidas à Jurisdição do Tribunal de Contas do Estado de Rondônia. Revista Científica Multidisciplinar Núcleo do Conhecimento. v.2, p.05-21, 2017.

TAI, S.; SONG, C.. Discussion of Environmental Audits Key Elements and Its Concept. Business and Management Research Journal, Toronto, v.2, n.1, 2013. DOI: http://doi.org/10.5430/bmr.v2n1p88

TODEA, N.; STANCIUS, I. C.; UDREA, A. M. J.. Environmental Audit, a possible source, of information for financial auditors. Annales Universitatis Apulensis Series Oeconomica, v.13, n.1, 2011. DOI: http://doi.org/10.29302/oeconomica.2011.13.1.7

VANDENBRANDE, W. W.. How to use FMEA to reduce the size of your quality toolbox. Quality Progress, v.31, n.11, p97-100, 1998.

VÉLEZ, P. E. R.; YÉPEZ, I. N. M.. El control ambiental a través de la auditoría como instrumento empresarial. Revista Domínio de las Ciências, v.3, n.1, p.525-535, 2017.

VIEIRA, F. P.. A Importância da Auditoria Ambiental para As Organizações. Revista Eletrônica da Facimed, v.3, n.3, p.266-280, 2011.

A CBPC - Companhia Brasileira de Produção Científica (CNPJ: 11.221.422/0001-03) detém os direitos materiais desta publicação. Os direitos referem-se à publicação do trabalho em qualquer parte do mundo, incluindo os direitos às renovações, expansões e disseminações da contribuição, bem como outros direitos subsidiários. Todos os trabalhos publicados eletronicamente poderão posteriormente ser publicados em coletâneas impressas sob coordenação da Sustenere Publishing, da Companhia Brasileira de Produção Científica e seus parceiros autorizados. Os (as) autores (as) preservam os direitos autorais, mas não têm permissão para a publicação da contribuição em outro meio, impresso ou digital, em português ou em tradução. 